\title{
Rol del docente como mediador de la formación de lectores en la educación básica
}

The role of the teacher as a mediator of the training of readers in

basic education

Recepción del artículo: 25-11-2020 ～Aceptación del artículo: 16-01-2021

Porfirio, Condori-Ojeda

Universidad Nacional Mayor de San Marcos

(Perú)

coporfirio@gmail.com

https://orcid.org/0000-0002-9017-2476
Para referenciar este artículo:

Condori-Ojeda, P. (2020). Rol del docente como mediador de la formación de lectores en la educación básica. Revista ConCiencia EPG,

6(1), 1-23.

https://doi.org/10.32654/CONCIENCIAEP

G.6-1.1

\section{Resumen}

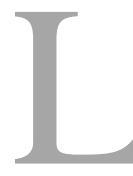

a formación del lector es un proceso de enseñanza aprendizaje permanente, que puede empezar en cualquier edad y nunca termina, por ello, se realizó este estudio con el objetivo de comprender las características de un docente lector y su percepción sobre el rol del docente mediador en la formación de lectores en la educación básica. El diseño es narrativo y fenomenológico, la muestra estuvo constituido por tres docentes lectores y a la vez escritores de las regiones Puno, Cusco y Ancash, de quienes se recogió información utilizando como técnica la entrevista y como instrumento la guía de entrevista semiestructurada de formación de lectores, que consta de treinta preguntas. El estudio concluye que, el docente es el elemento decisivo en el proceso de formación de lectores, para formar estudiantes lectores debe ser un asiduo lector. Además, los informantes claves coinciden en el principio de libertad como la esencia de dicho proceso, aunque las investigaciones de Álvarez-Álvarez y DiegoMantecón (2018) y Colomer y Munita (2013) evidencian que el maestro no es un lector experto y tiene serias limitaciones en su hábito lector, también en sus saberes y capacidades de interpretación de los textos.

Palabras Clave: formación de lectores, lector, mediador del aprendizaje, rol docente, educación básica. 


\section{Abstract}

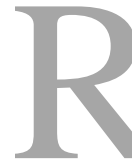

eader training is a lifelong learning teaching process, that can begin at any age and never ends, therefore, this study was carried out with the objective of understand the characteristics of a reading teacher and their perception of the role of the mediator teacher in the training of readers in basic education. The design is narrative and phenomenological, the sample consisted of three teacherreaders and at the same time writers from the Puno, Cusco and Ancash regions, from whom information was collected using the interview as a technique and the semistructured interview guide for the training of readers, consisting of thirty questions. It is concluded that the teacher is the decisive element in the process of training readers, to train student readers must be a regular reader. In addition, key informants agree on the principle of freedom as the essence of said process, although the investigations of Álvarez-Álvarez \& Diego-Mantecón (2018) and Colomer \& Munita (2013) show that the teacher is not an expert reader and has serious limitations in his reading habit, his knowledge and capacities of interpretation of the texts.

Key Words: Reader training, reader, learning mediator, teacher's role, basic education.

\section{Introducción}

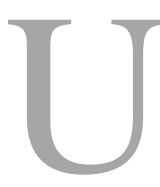

n estudio reciente de ÁlvarezÁlvarez y Pascual-Díez (2020) analiza la formación lectora de los docentes promotores de lectura y la literatura en educación básica y encontró que existen carencias en la formación lectora-literaria en los planes de estudio del profesorado, el tipo de práctica de educación lectora, sus concepciones y creencias didácticas. En esta perspectiva, esta investigación busca responder a la pregunta: ¿cuál es la percepción de los docentes lectores y escritores sobre el rol del docente como mediador de la formación de lectores en la educación básica? En este marco, se hacen alcance definiciones y concepciones relacionadas a las categorías de investigación: características del docente lectoescritor y rol del docente mediador en la formación de lectores.

Es indudable que la lectura (junto con la escritura) es uno de los ejes de todo proceso educativo y de importancia en todos los campas del concomimiento. Es "un complejo proceso de construcción de sentidos y significados que conducen al gozo estético, a la elaboración de todo tipo de conocimiento, a la emotividad $\mathrm{y}$, en última instancia, a un aprendizaje significativo" (Merlo, 2020, p. 5). Quién despliega habilidades en dicho proceso complejo es un lector, y ser lector según Garrido (2004) es aquel que lee por voluntad propia, lo hace todos los días y siempre trae consigo un libro con la esperanza de leerlo en algún momento; tiene la capacidad de comprender o atribuir significados a los textos, y si se le presenta alguna dificultad o no está satisfecho con el 
sentido que le da a un texto, lo resolverá de cualquier modo; es aquel que se sirve de la escritura, posee la capacidad de expresarse y comunicarse por escrito, y está habituado a adquirir libros. Para Devetach (2008) y Lerner (2002) tal camino del lector es un proceso de construcción de la autonomía un proceso que implica formación, porque como afirma Garrido (2004), el lector no nace, se hace.

La formación de lectores se distingue de otras categorías como fomento, animación y promoción. La formación de lectores es un proceso de enseñanza aprendizaje, es más que consumo de información $y$, en dicho proceso, la lectura es la actividad principal; por lo tanto, la formación de lectores tiene por finalidad formar el gusto por la lectura; a diferencia, los conceptos fomento, animación y promoción de lectura hacen alusión a la formación de hábitos en torno a dicha actividad (Mendoza-Valdés \& Cardoso-Malaquias, 2016). Considerar a la formación de lectores como proceso de alfabetización y consumo de libros por obligación es una hipótesis falsa (Garrido, 2004; Pennac, 1992; Sánchez, 1988). La formación de lectores es un asunto de escuela, de proyecto curricular institucional, que implica a todas las áreas curriculares y a todo el profesorado (Coll, 2004; Sainz, 2005; Solé, 2004), es un proceso transversal e interdisciplinar (Álvarez-Álvarez \& Pascual-Díez, 2013).

Para el Programme for Internacional Students Assesment (PISA, 2011) existe relación entre la lectura por placer y los resultados de las pruebas internacionales en lectura, según los resultados del estudio, entre los años 2000 a 2009 hubo una disminución de cinco puntos en la lectura por placer; además concluye que en promedio los estudiantes que leen a diario por placer obtienen una puntuación superior a un año y medio de escolarización en comparación a los que no lo hacen; la diferencias en el rendimiento en las evaluaciones en lectura reside en la lectura por placer. El primer elemento o el más importante para obtener mejores resultados en lectura en las evaluaciones PISA (2011) es la lectura por placer, los estudiantes que permanecen mucho tiempo disfrutando de la lectura, que además les gusta ir a la biblioteca o recibir como regalo un libro, tienen mejor desempeño en lectura (Caro, Espinosa \& Montané, 2004; Cueto, León, Muñoz \& Rosales, 2016). Por lo tanto, el rol del docente como mediador es importante para formar lectores (Feuerstein, 1993; Kaben, 2009; Sainz, 2005), sin esta mediación los estudiantes serían "privados culturales" (Feuerstein, 1993).

La mediación intencionada y trascendente permite el diálogo entre el estudiante, el saber y el docente. Según Not (1992) y De Zubiría (2006), subvaluar la función y el rol del mediador en el proceso de enseñanza aprendizaje interestructurante (que reconoce el papel activo del estudiante en el aprehendizaje, y a la vez reconoce el rol esencial $y$ determinante del docente mediador en el proceso; siendo un modelo dialogante que garantiza la síntesis dialéctica en la formación de lectores), es volver a los modelos heteroestructurante (donde el docente de manera rutinaria y mecánica propone e impone lo que se debe aprender 
o leer) o insistir con el modelo autoestructurante (que únicamente se centra en el aprendizaje y deja de lado la enseñanza y el docente se convierte en mero facilitador). Esto es, que la escuela y el docente tengan sensibilidad social, que el docente mediador se ocupe de su perfil lector, así como del perfil lector del estudiante, formándolo con el ejemplo, esfuerzo, afecto, felicidad, diálogo, pertinencia, creatividad, responsabilidad y trabajo (De Zubiría, 2006) y sobre todo tomando en cuenta las necesidades e intereses de aprendizaje o lectura de sus estudiantes.

A diferencia del aprendizaje (como proceso cognitivo mecánico), en todo aprehendizaje (aprendizaje significativo, con sentido, vinculado a la vida) tiene que ver con dimensiones humanas que implican enseñar a pensar, amar y actuar (De Zubiria, 2006); al respecto, basado en el enfoque histórico-cultural de Lev Vygotsky, Wallon (1984) expone tres dimensiones: la primera es aquella que está ligada al desarrollo del pensamiento que supondría, en el tópico que nos ocupa, incidir como docentes en la percepción que los niños y jóvenes tienen sobre la lectura, de modificar sensiblemente esa percepción; la segunda es la dimensión afectiva, la sociabilidad y los sentimientos, sin despertar el amor por los libros no hay aprendizaje, "no hay amor sin conocimiento ni conocimiento sin amor como decía Piaget" (De Zubiría, 2006), que establece una interdependencia entre el sistema cognitivo y el valorativo, siendo para la finalidad de este estudio implicaría una interrelación entre el saber leer y el querer leer por voluntad propia. La tercera dimensión es la praxis y la acción que trasciende la oralidad o el discurso de los sujetos de la educación; en todo caso, la formación de lectores requiere de un plan, un programa, un proyecto llevada a la acción. En consecuencia, la mediación docente implica el desarrollo interrelacionado, no excluyente, de las capacidades analíticas o cognitivas, socioafectivas, personales o valorativas y práxicas del estudiante, que le permita progresar de la situación real (no lector) en el que se encuentra a una situación de referencia ideal (lector) con la mediación y el feedback del docente (Ramaprasad, 1983).

\section{Método}

Diseño. El diseño de investigación es narrativo, ya que se "recolecta datos sobre las historias de vida y experiencias de determinadas personas para describirlas y analizarlas" (Salgado, 2007, párr. 23). Según Chase, Denzin y Lincoln (2015) "el modo en que los individuos narran la experiencia es tan importante para el significado que comunican" (p. 69). El tipo de estudio narrativo es de tópicos (Mertens, 2014) puesto que está enfocado en dos ejes temáticos: rol docente y formación de lectores. Es fenomenológico por cuanto se propone comprender una realidad de manera intencionada (Dutra, 2002).

Participantes. La obtención de información se concreta haciendo énfasis en los casos representativos o informantes claves (Martínez, 2015), a través del muestreo por bola de nieve o cadena, que permite identificar casos de interés (Martínez-Salgado, 2011), es decir, se 
identifican sujetos con capacidad de proporcionar información adoptando los criterios más adecuados para lograr los fines de la investigación (Patton, 1990). En cuanto a los criterios de inclusión, deben ser docentes de educación básica regular con experiencia en formación de lectores con perfil de lector y escritor de reconocida trayectoria profesional e intelectual, y de diferentes especialidades. Se identificó a 3 docentes: el primero de 42 años, con trece años de servicio en la región Cusco. El segundo informante tiene 55 años, con veintiocho años de servicio en la región Puno. El tercer informante tiene 26 años, con tres años de servicio en la región Ancash.

Material. Se utilizó como instrumento de investigación la guía de entrevista semiestructurada, consta de 30 preguntas que fueron categorizados en: características del docente lectoescritor, comporta cinco subcategorías: lee asiduamente por voluntad (preguntas 1 al 8), está habituado a comprender los textos (preguntas 9 al 11), adquiere libros continuamente (preguntas 12 al 14), se sirve de la escritura (preguntas 15 al 20) y, rol del docente mediador en la formación de lectores (preguntas 21 al 30).
Procedimientos. El cuestionario de entrevista se elaboró sobre la base de las propuestas de formación de lectores, una parte, de Garrido (2004), quien establece cinco características del lector: "lee por voluntad propia, lee todos los días, comprende lo que lee, puede servirse de la escritura, suele comprar libros" (p. 64); y la otra parte, en base al estudio realizado por Sainz (2005) referido a la importancia del mediador en la formación de lectores. Posteriormente, se efectuó la etapa del consentimiento informado a los informantes claves explicándoles la naturaleza del estudio y la importancia de su participación en la investigación. En seguida, se realizaron las entrevistas a los tres docentes en horarios convenidos mediante la aplicación de videoconferencia Google Meet, WhatsApp y llamadas telefónicas. El número de preguntas se fueron incrementando en el proceso como resultado del diálogo y la necesidad de profundizar y comprender la experiencia individual del docente sobre el fenómeno. Finalmente, realizada la trascripción se procedió con el análisis del discurso identificando las respuestas coincidentes, diferentes y discrepantes con las categorías y los sustentos teóricos

\section{Resultados}

\begin{tabular}{llll}
\hline Preguntas & Docente 1* & Docente 2** & Docente 3** \\
\hline $\begin{array}{l}\text { 1. ¿Qué te } \\
\text { gusta leer? }\end{array}$ & $\begin{array}{l}\text { Particularmente me } \\
\text { gustan los textos } \\
\text { literarios. Entre sus } \\
\text { diversos géneros me }\end{array}$ & $\begin{array}{l}\text { Artículos y libros, } \\
\text { preferentemente sobre } \\
\text { historia y literatura, de }\end{array}$ & $\begin{array}{l}\text { Artículos y libros } \\
\text { relacionados a la } \\
\text { educación basada en } \\
\text { proyectos, educación }\end{array}$ \\
& autores regionales, & nacionales e & basada en competencias, \\
\hline
\end{tabular}


quienes dialogan con los

textos que leo o que

escribo.

\begin{tabular}{|c|c|c|c|}
\hline $\begin{array}{l}\text { 5. ¿Cuáles } \\
\text { crees que son } \\
\text { las } \\
\text { características } \\
\text { de un docente } \\
\text { lector? }\end{array}$ & $\begin{array}{l}\text { Una de los rasgos más } \\
\text { importantes de un } \\
\text { docente lector es enseñar } \\
\text { con el ejemplo. Sobre } \\
\text { todo, cuando se trata de } \\
\text { estudiantes de secundaria } \\
\text { este asunto funciona } \\
\text { perfectamente ya que a } \\
\text { esa edad los jóvenes aún } \\
\text { se preocupan en emular a } \\
\text { sus maestros. }\end{array}$ & $\begin{array}{l}\text {-Que sea dialogante y } \\
\text { comparta lo aprendido } \\
\text { con sus estudiantes. } \\
\text {-Que sea un gran } \\
\text { motivador de la } \\
\text { escritura y la lectura. } \\
\text {-Que tenga un espíritu } \\
\text { crítico, para seleccionar } \\
\text { y sugerir textos y } \\
\text { autores. } \\
\text {-Que tenga programado } \\
\text { su tiempo para } \\
\text { enriquecer sus } \\
\text { conocimientos. } \\
\text {-Que tenga un espacio } \\
\text { para los libros y la } \\
\text { lectura. }\end{array}$ & $\begin{array}{l}\text { Tener bastante interés y } \\
\text { motivación por temas } \\
\text { específicos, tener } \\
\text { curiosidad, constancia y } \\
\text { ser autorreflexivo. }\end{array}$ \\
\hline $\begin{array}{l}\text { 6. ¿Crees que } \\
\text { todos los } \\
\text { docentes } \\
\text { pueden } \\
\text { formar } \\
\text { estudiantes } \\
\text { lectores? }\end{array}$ & $\begin{array}{l}\text { Definitivamente no. Leer } \\
\text { supone una serie de } \\
\text { acciones concretas, desde } \\
\text { tener una biblioteca hasta } \\
\text { ser un asiduo lector que } \\
\text { apuesta por salir adelante } \\
\text { invirtiendo en } \\
\text { conocimientos y } \\
\text { aprendizajes nuevos, ese } \\
\text { biotipo de docente que } \\
\text { asuma o tenga ese perfil } \\
\text { no lo encontramos y si } \\
\text { existe hay que buscarlo } \\
\text { con lupa. }\end{array}$ & $\begin{array}{l}\text { Quienes han elegido la } \\
\text { profesión docente por } \\
\text { voluntad propia tienen el } \\
\text { talento suficiente para } \\
\text { formar lectores; claro que } \\
\text { unos tienen más éxito que } \\
\text { otros. El trabajo docente } \\
\text { debe complementarse con } \\
\text { el apoyo familiar. }\end{array}$ & $\begin{array}{l}\text { La lectura es necesaria } \\
\text { para poder generar } \\
\text { productos nuevos en los } \\
\text { estudiantes, los docentes } \\
\text { pueden generar } \\
\text { estudiantes lectores } \\
\text { siempre y cuando dichos } \\
\text { profesores hayan } \\
\text { detectado o despertado } \\
\text { los temas de interés en } \\
\text { los estudiantes. }\end{array}$ \\
\hline $\begin{array}{l}\text { 7. ¿Cómo se } \\
\text { desarrolla el } \\
\text { Plan lector en } \\
\text { la institución } \\
\text { educativa en el } \\
\text { que trabajas? }\end{array}$ & $\begin{array}{l}\text { El plan lector se asume de } \\
\text { tres modos: el primero es } \\
\text { personal, parte del tipo de } \\
\text { docente y las lecturas que } \\
\text { planifica para sus } \\
\text { estudiantes. El segundo es } \\
\text { por tipo de área } \\
\text { pedagógica, es decir, una } \\
\text { determinada área toma } \\
\text { por grupo de lectura a los } \\
\text { textos que ellos vean por } \\
\text { conveniente. Y el tercer }\end{array}$ & $\begin{array}{l}\text { Participamos todos los } \\
\text { docentes dirigidos por los } \\
\text { profesores de } \\
\text { Comunicación. Nos } \\
\text { reunimos por grados } \\
\text { docentes y estudiantes } \\
\text { para elegir los textos y las } \\
\text { actividades a realizarse. } \\
\text { Hace tres años se logró } \\
\text { leer, en promedio, un libro, }\end{array}$ & $\begin{array}{l}\text { El área de Comunicación } \\
\text { desarrolla el plan lector } \\
\text { de acuerdo a un } \\
\text { programa organizado } \\
\text { por la UGEL, en la que } \\
\text { semanalmente proponen } \\
\text { lecturas. }\end{array}$ \\
\hline
\end{tabular}


modo es el plan lector

institucional, es el modo

donde toda la institución

lee de acuerdo a

cronogramas, topologías

textuales y demás datos

que orientan la lectura

con un propósito

señalado en el documento

que norma dicho plan. y el año pasado se logró

dos.

$\begin{array}{ll}\begin{array}{l}\text { 8. ¿Consideras } \\ \text { que los }\end{array} & \begin{array}{l}\text { No creo que haya mucho } \\ \text { vínculo debido a PISA está } \\ \text { resultados en } \\ \text { lectura de }\end{array} \\ \begin{array}{l}\text { PISA están } \\ \text { además PISA no enfoca } \\ \text { relacionados } \\ \text { con la }\end{array} & \begin{array}{l}\text { necesidades y rasgos } \\ \text { distintivos que nuestros }\end{array} \\ \text { formación de } & \text { estudiantes tienen. Por } \\ \text { lectores en la } & \text { ello pienso que otras } \\ \text { educación } & \text { formas evaluativas que se } \\ \text { básica? } & \text { dan en nuestro entorno sí } \\ & \text { forman lectores. }\end{array}$

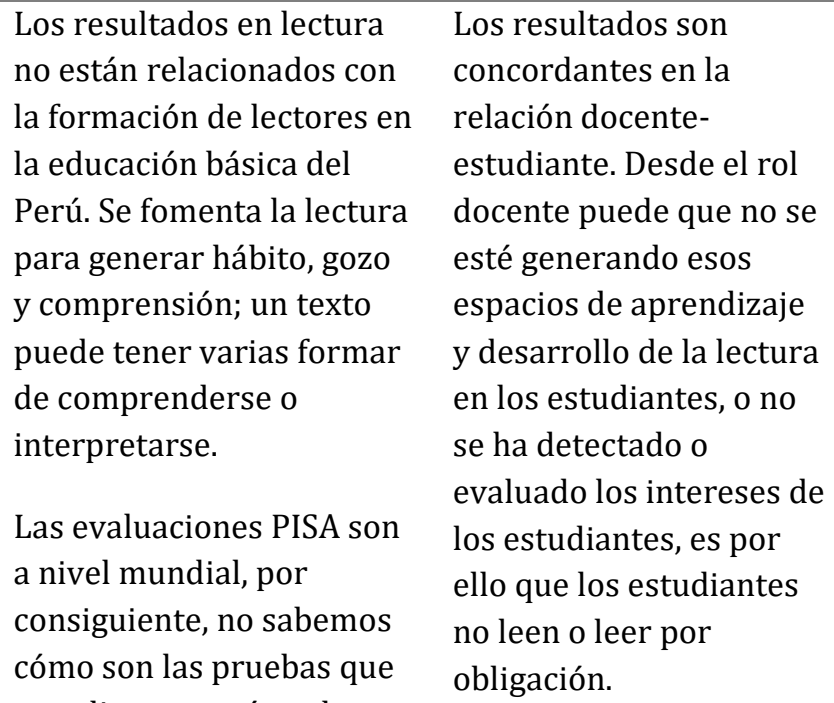

se aplican en países de otros continentes.

\begin{tabular}{llll}
\hline 9. ¿Cómo lees & Bueno, la forma en que & La lectura intensiva y & Tomo notas mientras \\
un texto? & leo es según el tipo de & silenciosa, la realizo en el & avanzo con la lectura, mi \\
texto que leo. Muchas & tiempo y espacio & estrategia se basa en \\
veces leo por encargo & adecuado, con música & obtener resúmenes \\
(para trabajos de & instrumental y con los & constantemente para \\
& investigación o por ejes & materiales básicos. & poder de manera rápida \\
temáticos de revistas que & & recordar puntos \\
piden artículos, reseñas, o & Para los estudiantes leo & importantes o claves de \\
& ensayos de un & breves textos en voz alta y & los textos que leo. Me \\
& determinado libro), por & luego comentamos. & toma un poco más de \\
& placer textual (cuando leo & & tiempo, pero los \\
& poesía o narrativa que me & & resultados de obtener \\
& agrada por la firma del & & información son \\
& autor o el género), este & & satisfactorios. \\
& placer me permite leer un & & \\
& único texto dos o tres & & \\
& veces. En realidad, hay &
\end{tabular}


muchas formas de leer 0

enfrentarse al texto.

10. ¿Qué
sueles hacer
cuando una
parte del texto
te resulta poco
comprensible?

Normalmente releo. Esa estrategia siempre me ha funcionado.

11. ¿Crees que los que leen con autonomía tienen mayor facilidad para comprender los textos escritos?

\section{Evidentemente que sí,} cuando lees con autonomía fluye más la lectura, permitiendo que la dualidad libro-lector sean uno solo y se compenetren, eso es muy importante ya que cuando te obligan a leer no puedes hacer eso. La lectura obligada ahuyenta al lector.

\author{
Vuelvo a leer el párrafo, \\ acudo al diccionario, \\ reviso en el internet. \\ Pongo un signo de \\ interrogación en el margen \\ del párrafo poco \\ comprensible.
}

\section{Considero que sí. La} autonomía está relacionada con la libertad y la voluntad. Si uno adquiere un texto de manera libre es muy seguro que le encanta la lectura, y quien se deleita leyendo es casi seguro que comprende lo que lee.
Busco información confiable en internet hasta lograr entender algún concepto que no lo haya tenido claro.

\begin{tabular}{|c|c|c|c|}
\hline $\begin{array}{l}\text { 12. ¿Con qué } \\
\text { frecuencia } \\
\text { adquieres u } \\
\text { obtienes libros } \\
\text { u otros } \\
\text { materiales de } \\
\text { lectura? }\end{array}$ & $\begin{array}{l}\text { No tengo una frecuencia } \\
\text { específica, pues leo desde } \\
\text { inhallables libros gracias } \\
\text { a las redes vía PDF y } \\
\text { también libros físicos } \\
\text { según los voy } \\
\text { encontrando en ferias o } \\
\text { tiendas de suelo. Rara vez } \\
\text { hago pedidos de librerías } \\
\text { lejanas o por préstamos } \\
\text { de bibliotecas, aunque } \\
\text { estas últimas nunca han } \\
\text { tenido los libros que } \\
\text { busco. }\end{array}$ & $\begin{array}{l}\text { No tengo una frecuencia } \\
\text { establecida. Los adquiero } \\
\text { cada vez que los necesito o } \\
\text { están a mi alcance. Todo } \\
\text { depende de los recursos } \\
\text { con que cuento, pero está } \\
\text { dentro de mis prioridades. }\end{array}$ & $\begin{array}{l}\text { Semanalmente obtengo } \\
\text { libros digitales, y libros } \\
\text { que los veo bastante } \\
\text { interesantes, los } \\
\text { imprimo y los anillo para } \\
\text { tener libros en físico y } \\
\text { poder ojearlos en } \\
\text { cualquier parte del día. }\end{array}$ \\
\hline $\begin{array}{l}\text { 13. ¿Qué libros } \\
\text { o materiales } \\
\text { de lectura } \\
\text { adquieres con } \\
\text { frecuencia? }\end{array}$ & $\begin{array}{l}\text { Con una frecuencia } \\
\text { normal adquiero libros de } \\
\text { poesía y narrativa. Que } \\
\text { son los géneros que leo } \\
\text { casi por necesidad debido } \\
\text { a que escribo o siempre } \\
\text { estoy en correcciones de } \\
\text { nuevos libros que a veces }\end{array}$ & $\begin{array}{l}\text { Priorizo los libros } \\
\text { relacionados con la } \\
\text { historia, pedagogía, } \\
\text { derecho, economía, } \\
\text { filosofía, sociología, } \\
\text { personajes, etc.; también } \\
\text { son de mi predilección las } \\
\text { obras literarias en general, }\end{array}$ & $\begin{array}{l}\text { Libros en PDF sobre } \\
\text { desarrollo de } \\
\text { identidades, desarrollo y } \\
\text { aprendizaje, habilidades } \\
\text { matemáticas en niños. }\end{array}$ \\
\hline
\end{tabular}

Los que usualmente leen con autonomía suelen detectar temas de su interés con más facilidad. 
nunca termino de escribir. sobre todo de autores

reconocidos. Adquiero

también normas legales

sobre educación.

$\begin{array}{ll}\begin{array}{ll}\text { 14. ¿En qué } \\ \text { formato }\end{array} & \begin{array}{l}\text { Definitivamente los libros } \\ \text { físicos pues son los únicos }\end{array} \\ \text { prefieres los } & \text { que te permiten un sinfín } \\ \text { libros?, ¿en } & \text { de cosas. Solo por citar } \\ \text { físico, en } & \text { diré los subrayados o } \\ \text { digital u otros? } & \text { alguna técnica de lectura. }\end{array}$

Los prefiero en físico para

sentir el perfume del tiempo. Además, porque en las hojas se pueden aplicar múltiples técnicas antes, durante y después de la lectura; además es más práctico y enriquece la biblioteca.
En ambos, la ventaja de los libros digitales es que los puedes llevar en la nube o en el celular a todas partes, y de los físicos es que puedes tomar apuntes o detenerte en ciertas partes para volverlo a repasar, tomar apuntes o resaltar ideas con facilidad.

Actualmente estoy escribiendo diagnósticos u observaciones que realizo a los niños, me permite analizar casos reales.

es lo que más

escribes?

geografía y personajes de

Juliaca, así como

narraciones y artículos

académicos y de opinión.

\begin{tabular}{|c|c|c|c|}
\hline $\begin{array}{l}\text { 16. De todas } \\
\text { tus } \\
\text { publicaciones, } \\
\text { ¿cuál crees } \\
\text { que es el más } \\
\text { importante? }\end{array}$ & $\begin{array}{l}\text { Solo los críticos literarios } \\
\text { pueden decir cuál es el } \\
\text { más importante de los } \\
\text { libros que uno publica, es } \\
\text { difícil que uno mismo } \\
\text { pueda mencionar algo así, } \\
\text { sería ilegal e incierto. }\end{array}$ & $\begin{array}{l}\text { El libro Temas históricos de } \\
\text { Juliaca que tiene cinco } \\
\text { ediciones. }\end{array}$ & $\begin{array}{l}\text { Los diagnósticos que } \\
\text { estoy escribiendo me } \\
\text { servirán como base para } \\
\text { investigaciones futuras y } \\
\text { experiencia en aula. }\end{array}$ \\
\hline $\begin{array}{l}\text { 17. ¿Publicaste } \\
\text { libros con tus } \\
\text { estudiantes o } \\
\text { con otros } \\
\text { docentes? } \\
\text { Podrías } \\
\text { mencionarlos. }\end{array}$ & $\begin{array}{l}\text { Publiqué algunos libros } \\
\text { con estudiantes, pero } \\
\text { fueron en tirajes } \\
\text { reducidos pues no } \\
\text { pasaban el medio millar. } \\
\text { Esto debido a que su } \\
\text { circulación iba a ser solo } \\
\text { dentro de la institución. } \\
\text { Fueron algo de } 3 \text { títulos } \\
\text { que iban sobre narrativa } \\
\text { breve. }\end{array}$ & $\begin{array}{l}\text { Publicamos revistas } \\
\text { informativas con } \\
\text { profesores y estudiantes, } \\
\text { destacan: Despertar } \\
\text { mercedario, Bodas de Oro } \\
\text { del Politécnico, Sinopsis } \\
\text { histórica de la GUE Las } \\
\text { Mercedes, entre otras. }\end{array}$ & $\begin{array}{l}\text { Aún no lo he publicado, } \\
\text { pero tengo ese proyecto } \\
\text { en proceso. }\end{array}$ \\
\hline
\end{tabular}

escribidor informal o

formal. He escrito algunos

textos sobre historia 


\begin{tabular}{llll}
\hline $\begin{array}{l}\text { 18. ¿Te gusta } \\
\text { compartir tus }\end{array}$ & Normalmente no & Sí. Los primeros lectores & En esta educación a \\
publicaciones & de mis textos son los & distancia me gusta \\
con los & que no se conecta con & & compartir creaciones \\
estudiantes? & ellos el tema o el género & mediante \\
& que escribo. Sin embargo, & WhatsApp, dichos textos \\
& en los últimos años, he & son \\
& estado publicando libros & informativos/educativos. \\
& direccionados, es decir & \\
& libros que se puedan & \\
& conectar con ellos para & \\
& compartirlos en el salón & \\
& de clases.
\end{tabular}

\begin{tabular}{ll}
\hline $\begin{array}{l}\text { 19. ¿Crees que } \\
\text { tener un }\end{array}$ & $\begin{array}{l}\text { De alguna manera pienso } \\
\text { que sí, debido a que como } \\
\text { docente }\end{array}$ \\
señalé líneas arriba, la \\
lectoescritor & enseñanza se da con el \\
motiva a la & ejemplo. Muchos \\
lectura a los & estudiantes imitan a sus \\
estudiantes? & docentes y las cosas que \\
& para ellos era difícil, pues \\
& con sus docentes \\
& lectoescritores las ven \\
& alcanzables.
\end{tabular}

Todo docente es un motivador de la lectura, y si además es lectoescritor enfatiza esta motivación; pero se debe tener mucho cuidado y no irradiar imagen de petulancia en los estudiantes.
Es vital que un docente sea lectoescritor, ya que al tener dicha capacidad desarrollada puede entender las dificultades y necesidades en sus estudiantes al momento de incentivarlos a leer y escribir.

\begin{tabular}{|c|c|c|c|}
\hline $\begin{array}{l}20 . \text { ¿Crees que } \\
\text { la lectura y } \\
\text { escritura son } \\
\text { procesos } \\
\text { cognitivos que } \\
\text { se } \\
\text { complementan } \\
\text { y se } \\
\text { refuerzan? }\end{array}$ & $\begin{array}{l}\text { Pues sí, son necesidades. } \\
\text { La lectura siempre va } \\
\text { adelante. No puede existir } \\
\text { alguien que escriba sin } \\
\text { antes haber leído. Solo los } \\
\text { buenos textos nacen de } \\
\text { un lector. }\end{array}$ & $\begin{array}{l}\text { Afirmativo. Los } \\
\text { estudiantes lo saben, pero } \\
\text { la pereza intelectual los } \\
\text { domina. } \\
\text { Para escribir se tiene que } \\
\text { leer y todo lo que está } \\
\text { escrito es para ser leído. } \\
\text { Tanto la lectura como la } \\
\text { escritura se } \\
\text { complementan y se } \\
\text { refuerzan mutuamente. }\end{array}$ & $\begin{array}{l}\text { Tanto la lectura, la } \\
\text { expresión oral y la } \\
\text { escritura se } \\
\text { complementan } \\
\text { continuamente. Ello no } \\
\text { sólo los ayudará a } \\
\text { formarse como } \\
\text { lectoescritores, sino les } \\
\text { permitirá el desarrollo } \\
\text { de otras competencias } \\
\text { de otras áreas y las } \\
\text { competencias } \\
\text { transversales. }\end{array}$ \\
\hline $\begin{array}{l}\text { 21. ¿En la } \\
\text { actualidad, } \\
\text { qué tipos de } \\
\text { textos } \\
\text { prefieren leer }\end{array}$ & $\begin{array}{l}\text { En este siglo y con las } \\
\text { redes sociales al tope, los } \\
\text { textos que todos los } \\
\text { estudiantes desean leer } \\
\text { son muy breves. }\end{array}$ & $\begin{array}{l}\text { Los estudiantes prefieren } \\
\text { textos cortos. } \\
\text { Generalmente de } \\
\text { motivación personal y } \\
\text { narrativa breve. La }\end{array}$ & Textos instructivos \\
\hline
\end{tabular}




\begin{tabular}{lll}
\hline $\begin{array}{l}\text { los } \\
\text { estudiantes? }\end{array}$ & $\begin{array}{l}\text { Instagram les ha dado la } \\
\text { medida y el ejemplo. }\end{array}$ & $\begin{array}{l}\text { mayoría opta por textos } \\
\text { digitales. }\end{array}$ \\
& \\
& $\begin{array}{l}\text { Pero la lectura voluntaria, } \\
\text { en la mayoría de casos, no }\end{array}$ \\
& es una prioridad en los \\
& escolares de hoy.
\end{tabular}

\begin{tabular}{|c|c|c|c|}
\hline $\begin{array}{l}\text { 22. ¿Qué } \\
\text { elementos } \\
\text { consideras } \\
\text { indispensables } \\
\text { para la } \\
\text { formación de } \\
\text { lectores en } \\
\text { educación } \\
\text { básica? }\end{array}$ & $\begin{array}{l}\text { Creo que lo más } \\
\text { importante para una } \\
\text { formación de lectores no } \\
\text { solo es una biblioteca } \\
\text { adecuada, sino la } \\
\text { predisposición que debe } \\
\text { existir en el lector. Otro } \\
\text { aspecto es un plan de } \\
\text { lectura que oriente los } \\
\text { procesos de este tipo de } \\
\text { aprendizaje. }\end{array}$ & $\begin{array}{l}\text { - Textos al alcance de los } \\
\text { estudiantes. Sin textos } \\
\text { no hay lectura. } \\
\text { - Cantidad: cada } \\
\text { estudiante con su texto y } \\
\text { textos para cada } \\
\text { estudiante. } \\
\text { - Motivación } \\
\text { - Interés: la voluntad y la } \\
\text { atención deben estar } \\
\text { dirigidos a la } \\
\text { comprensión del texto. } \\
\text { - Conocimiento: saber } \\
\text { reconocer “un buen } \\
\text { texto” y las ideas } \\
\text { relevantes. } \\
\text { - Técnicas }\end{array}$ & $\begin{array}{l}\text { El monitoreo constante } \\
\text { del docente, el diseño de } \\
\text { espacios de aprendizaje, } \\
\text { la elección asertiva de } \\
\text { tareas o materiales para } \\
\text { incentivar la } \\
\text { lectoescritura. }\end{array}$ \\
\hline $\begin{array}{l}\text { 23. ¿Cuál es la } \\
\text { secuencia } \\
\text { didáctica que } \\
\text { sigues para } \\
\text { fomentar el } \\
\text { gusto por la } \\
\text { lectura? }\end{array}$ & $\begin{array}{l}\text { Una de las secuencias } \\
\text { didácticas que facilita la } \\
\text { lectura es poder ordenar } \\
\text { adecuadamente los } \\
\text { procesos que implica el } \\
\text { ejercicio lector. Primero } \\
\text { busco el gusto libre por la } \\
\text { lectura, luego impartimos } \\
\text { las bases teóricas de la } \\
\text { comprensión lectora que } \\
\text { son las herramientas con } \\
\text { las que al final se } \\
\text { enfrentará al texto en } \\
\text { distintas modalidades. Es } \\
\text { muy importante saber } \\
\text { distinguir ¿Qué deseamos } \\
\text { explicar, un término, un } \\
\text { concepto o una teoría? ¿O } \\
\text { todo a la } \\
\text { vez? ¿Qué queremos que } \\
\text { el alumnado asimile? }\end{array}$ & $\begin{array}{l}\text { Considero tres fases: } \\
\text { Antes, durante y después. } \\
\text { Realizo un breve } \\
\text { diagnóstico exploratorio } \\
\text { de la situación sobre los } \\
\text { intereses, propósitos, } \\
\text { motivaciones y la } \\
\text { naturaleza del texto. } \\
\text { Durante la lectura se } \\
\text { aplican determinadas } \\
\text { técnicas como el } \\
\text { subrayado, el } \\
\text { reconocimiento de } \\
\text { palabras que no } \\
\text { entendemos, dialogamos } \\
\text { sobre preguntas que } \\
\text { surgen en esos momentos, } \\
\text { etc. Al final de la lectura se } \\
\text { dialoga sobre el contenido } \\
\text { del texto, se asumen } \\
\text { compromisos y se elabora } \\
\text { un resumen esquemático. }\end{array}$ & $\begin{array}{l}\text { Detectar temas de } \\
\text { interés en los } \\
\text { estudiantes, realizar } \\
\text { preguntas retadoras, } \\
\text { generar espacios de } \\
\text { diálogo y opinión, lanzar } \\
\text { materiales textuales que } \\
\text { les puedan ayudar a } \\
\text { mejorar en su } \\
\text { comprensión o fortalecer } \\
\text { sus aprendizajes, acorde } \\
\text { a las preguntas } \\
\text { retadoras planteadas. } \\
\text { Termina con entrega de } \\
\text { evidencias que incluyen } \\
\text { tareas concretas a } \\
\text { realizar, como los } \\
\text { apuntes que los } \\
\text { estudiantes hayan } \\
\text { tomado de las lecturas. }\end{array}$ \\
\hline
\end{tabular}

23. ¿Cuál es la secuencia didáctica que sigues para fomentar el gusto por la usco el gusto libre por la lectura, luego impartimos las bases teóricas de la las que al final se enfrentará al texto en distintas modalidades. Es muy importante saber distinguir ¿Qué deseamos explicar, un término, un cepto o una teoría? ¿O vez? ¿Qué queremos que el alumnado asimile?

\section{Considero}

Realizo un breve diagnóstico exploratorio de la situación sobre lo intereses, propósitos, lexto.

Durante la lectura se técnicas como el subrayado, e palabras que no entendemos, dialogamos sobre preguntas que surgen en esos momentos, etc. Al final de la lectura se dialoga sobre el contenido promisos y se elabora un resumen esquemático. 


\begin{tabular}{ll}
\hline 24. ¿Qué & La comprensión lectora \\
estrategias o & puede desarrollarse de \\
propuestas de & distintas formas, sin \\
formar & embargo, lo más \\
lectores & importante consiste en \\
conoces? & saber qué saben y pueden \\
& saber los estudiantes con \\
& nuestra ayuda. La \\
& mediación no debe \\
& reducirse a ofrecer \\
& conocimientos, pues así \\
& no existirán situaciones \\
& de aprendizaje activo por \\
& ningún lado. Y cuando \\
& esto suceda, no es que no \\
& haya lectura comprensiva, \\
& es que ni siquiera habrá \\
& aprendizaje. Por ello se \\
& debe tener propuestas \\
& activas y de interactividad \\
& constante. Cada una \\
& implica una infinidad de \\
& rasgos y secuencias que \\
& sería muy extenso \\
& explicar aquí. \\
& \\
& \\
& \\
& \\
& \\
& \\
& \\
& \\
&
\end{tabular}

Conozco algunas como:

- La hora de lectura (Minedu)

- Leemos todos (Minedu)

- Escuela de lectores y escritores.

- El cuentacuentos.

- Los libros valoran mi cultura.
Un docente recolectó historias y cuentos de los estudiantes, y finalmente consiguió ilustrarlos y obtener como producto libros en físico y que los estudiantes pudiesen leer y buscar sus propias historias que había creado/escrito.

\begin{tabular}{ll}
\hline 25. ¿Cuáles de & $\begin{array}{l}\text { Hay una estrategia que } \\
\text { esas }\end{array}$ \\
siempre funciona, es la \\
estrategias & denominada 'lectura \\
con más & que un estudiante elige \\
viables en la & un libro con 3 razones \\
formación de & que lo implican a él y al \\
estudiantes & libro. Funciona de \\
lectores? & maravillas pues \\
& normalmente lo lee en \\
& una sentada. Otra que \\
& también funciona se llama \\
& FANFICTION que se usa \\
& solo con lecturas de \\
& ficción. Tiene varios \\
& procesos.
\end{tabular}

En tiempo de pandemia, la
mejor estrategia es la
propuesta de "leemos
todos", porque
compromete la
participación de la familia.

En tiempos de escolarización presencial las estrategias que ofrecen mejores resultados es la "escuela de lectores y escritores" y "los libros valoran mi cultura"
El uso de la escritura para plasmar temas de tu interés, usar la escritura como medio de expresión y manifestación cultural.

\begin{tabular}{llll}
\hline $\begin{array}{l}\text { 26. ¿Qué tipos } \\
\text { de texto }\end{array}$ & $\begin{array}{l}\text { Normalmente se emplea } \\
\text { textos breves de ficción, }\end{array}$ & $\begin{array}{l}\text { En el aula, para una sesión } \\
\text { trabajamos textos poco }\end{array}$ & $\begin{array}{l}\text { Textos informativos, } \\
\text { infografías. } \\
\text { utilizas para }\end{array}$ \\
\hline
\end{tabular}


propiciar el gusto por la lectura en los estudiantes? calan en el estudiante, pero lo más importante es que deben estar conectados con el lector. textos seleccionados en el

Plan lector.

En los primeros grados utilizamos textos literarios o narrativos con temáticas, preferentemente, andinas.

En los últimos grados textos y obras clásicas de la cultura nacional y universal.

\begin{tabular}{ll}
\hline 27. ¿Qué & Siempre han sido muy \\
dificultades & limitantes las \\
enfrentas en & programaciones del \\
tu trabajo & MINEDU y el tiempo que \\
pedagógico en & existe para trabajar ese \\
tu afán de & asunto. Las \\
formar & programaciones porque \\
lectores? & debemos cumplir temas \\
& programados que muchas \\
& veces suponen un \\
& obstáculo pues, muchas \\
& veces, solo son temas \\
& periféricos al eje lector.
\end{tabular}

\begin{tabular}{|c|c|c|c|}
\hline $\begin{array}{l}\text { 28. ¿Cuál crees } \\
\text { que es el rol } \\
\text { del } \\
\text { profesorado } \\
\text { de educación } \\
\text { básica en el } \\
\text { proceso de } \\
\text { formación de } \\
\text { lectores? }\end{array}$ & $\begin{array}{l}\text { El rol es muy amplio, pero } \\
\text { las limitaciones son más. } \\
\text { Sin embargo, el rol } \\
\text { fundamental no solo es de } \\
\text { guía, sino de desarrollar } \\
\text { el trabajo de hacer } \\
\text { diferencias en los } \\
\text { mecanismos de la lectura, } \\
\text { lejos incluso de aquella } \\
\text { idea donde muchas } \\
\text { personas creen que leer } \\
\text { consiste en oralizar la } \\
\text { grafía, en devolver la voz } \\
\text { a la letra callada. }\end{array}$ & $\begin{array}{l}\text { Su rol es de ser un } \\
\text { empecinado promotor de } \\
\text { la lectura comprensiva, } \\
\text { para ello deberá: insistir } \\
\text { en generar hábitos } \\
\text { lectores en los estudiantes } \\
\text { a su cargo, desarrollar } \\
\text { estrategias para la } \\
\text { comprensión lectora, } \\
\text { mostrar paciencia y } \\
\text { empatía hacia los lectores } \\
\text { potenciales. }\end{array}$ & $\begin{array}{l}\text { Incentivar o crear } \\
\text { espacios de aprendizaje, } \\
\text { elegir tareas según el } \\
\text { nivel de dificultad o } \\
\text { demanda cognitiva, } \\
\text { diagnosticar a sus } \\
\text { propios estudiantes para } \\
\text { planificar sesiones de } \\
\text { aprendizaje adaptadas a } \\
\text { la realidad del } \\
\text { estudiante, buscando } \\
\text { que las lecturas } \\
\text { permitan desarrollar sus } \\
\text { competencias. }\end{array}$ \\
\hline $\begin{array}{l}29 . \\
\text { ¿Consideras } \\
\text { que el } \\
\text { Currículo }\end{array}$ & $\begin{array}{l}\text { Definitivamente que no. } \\
\text { Todas las líneas }\end{array}$ & $\begin{array}{l}\text { El Currículo Nacional no } \\
\text { está diseñado para formar } \\
\text { lectores, sino que contiene } \\
\text { lineamientos generales }\end{array}$ & $\begin{array}{l}\text { Creo que sí. El detalle es } \\
\text { al momento de llevar a la } \\
\text { práctica/aula se omite } \\
\text { ciertos aspectos, o se }\end{array}$ \\
\hline
\end{tabular}

La primera dificultad es la Actualmente se tienen escasez de textos. No todos dificultades al momento los estudiantes tienen la de realizar clases de capacidad de adquirir uno. forma asíncrona y Hay estudiantes que se mediante WhatsApp, ya prestan un libro, y en esas que es el único medio condiciones no se pueden por el cual pueden aplicar técnicas durante la contactarse los lectura. estudiantes por los escasos recursos económicos. Las lecturas o estrategias no suelen llegar a la totalidad de estudiantes. 


\begin{tabular}{|c|c|c|c|}
\hline $\begin{array}{l}\text { Nacional de } \\
\text { Educación } \\
\text { Básica está } \\
\text { diseñado para } \\
\text { formar } \\
\text { lectores? }\end{array}$ & $\begin{array}{l}\text { anteriores apuntan a esta } \\
\text { negativa. }\end{array}$ & $\begin{array}{l}\text { que pretende desarrollar } \\
\text { casi treinta competencias, } \\
\text { dentro de ellas se } \\
\text { encuentra la competencia } \\
\text { de leer y escribir diversos } \\
\text { tipos de textos. }\end{array}$ & $\begin{array}{l}\text { desarrolla } \\
\text { erróneamente. A los } \\
\text { docentes les falta } \\
\text { interiorizarlo y proponer } \\
\text { ejecución efectiva de } \\
\text { desarrollo de } \\
\text { desempeños y } \\
\text { capacidades de las } \\
\text { competencias. }\end{array}$ \\
\hline
\end{tabular}

30. ¿Cuál es tu
propuesta de
formación de
lectores en
educación
básica?

La más actual quizá tenga
que ver con la libertad del
lector frente al texto, que
tiene que ver con el afán
de conectarse libremente
con un texto para que luego desarrolle un vínculo texto-lector y se genere así el tan manido hábito lector. Formarlos desde temprana edad con un amor filial por la lectura, pues solo cuando el estudiante tiene la oportunidad de valorar y destacar la universalidad y la igualdad de la lectura. Puesto que solo leyendo se dará cuenta que leer requiere desarrollar procesos cognitivos, $\mathrm{y}, \mathrm{a}$ la vez, ponerlos en práctica porque sabrá que le harán falta y que necesita de leer para vivir.

\section{Mi propuesta se titula: \\ "Frases motivadoras".}

Las sesiones presenciales

para fomentar la lectura empiezan con una frase, lema o pensamiento que se encuentra en el texto que luego se leerá.

Antes de leer se hace una breve explicación del contexto del texto y de la trascendencia del autor. Se formulan preguntas motivadoras y luego iniciamos con la lectura.

Las primeras lecturas serán de textos cortos y luego se avanzarán hacia libros amplios y complejos que elijan los mismos estudiantes.
Utilizando el Currículo

Nacional de Educación Básica, mi propuesta es generar la escritura a través de la necesidad de los estudiantes, acorde a la realidad de los estudiantes. Los estudiantes logran hábitos de escritura y lectura según se sientan cómodos con las temáticas y contextos donde viven. La adaptación de contenidos es vital en ese aspecto, la tarea de los docentes es buscar situaciones auténticas como insumo de motivación para que los estudiantes puedan leer.

\footnotetext{
*Darwin Bedoya Bautista, docente de Comunicación con grado académico de Magíster en Educación, es poeta y narrador. Ganador del Premio Copé Internacional de Oro 2011 y Premio Nacional Horacio 2015. Miembro permanente del Consejo Editorial de las revistas de literatura Pez de oro y El Katari en Perú.

**Hugo Didí Apaza Quispe, docente de Historia y Geografía con grado académico de Magíster en Educación, es historiador, autor de Temas históricos de Juliaca (2016) y La gesta de 4 de noviembre (2016).

*** Ronald Wilson Machaca Hancco, docente de Educación Primaria, economista, promotor de lectura y miembro de la ONG Enseña Perú.
} 
Respecto a la concepción sobre las características del docente en la formación de lectores en educación básica se encontró lo siguiente:

El docente 1 afirma que, para formar lectores el docente tendría que, además de tener una biblioteca, ser un asiduo lector que apuesta por invertir en conocimiento y aprendizajes nuevos, que tenga motivaciones relevantes para leer, como el hecho de actualizarse en enfoques literarios, propuestas estéticas, recrear sus sentidos, escribir una reseña, o por el gusto de leer; que el docente se nutra de nuevos acervos continuamente, que enseña con el ejemplo sobre todo en educación básica, porque a temprana edad los estudiantes son más receptivos, los estudiantes intentarán emular a sus maestros porque con sus docentes lectoescritores ven como alcanzable el acto de disfrutar de la lectura; además, el docente con perfil de formador de lectores es quien comparte con sus estudiantes lo que lee y escribe, induciéndolos al diálogo con los textos, contagiándoles la actitud de asumir el reto de desentrañar los textos complejos y escribir su versión propia de la lectura, a través de la relectura, el uso del subrayado. Opina que la planificación de la lectura, en primer lugar, comienza por el docente quien selecciona los textos para sus estudiantes, en segundo lugar, según área curricular; y, por último, es institucional, modalidad en el que toda la institución lee de acuerdo al cronograma y las normas del plan. El plan de lectura debe responder a propósitos que van más allá de la comprensión como la publicación de microrrelatos, en cuyo proceso, según el entrevistado, se debe integrar la dualidad libro-lector, lectura escritura, anteponiendo la lectura sobre la escritura porque "los buenos textos nacen de un lector". Un proceso que no ahuyente al estudiante con la lectura obligada.

El docente 2 afirma, para formar lectores uno debe sentir el goce al entrar en contacto con las obras y sus autores, con los nuevos datos que este le ofrece, así como las interpretaciones que inducen a cambiar la forma de pensar sobre los hechos, o el manejo del lenguaje y los recursos retóricos si se tratan de literatura. Considera que un formador de lectores comparte la pasión por la materia que enseña, lo hace por medio del diálogo, la motivación constante, con espíritu crítico, generando tiempo y espacios para los libros y la lectura. Refiere que el docente que ha elegido la profesión por voluntad posee el talento para formar lectores, sobre todo cuando el trinomio docente-estudiante-familia se complementan, aunque es consciente que no todos los docentes tienen el mismo éxito con sus estudiantes, aun cuando exista un plan de lectura institucional e interdisciplinar dirigido por docentes del área de comunicación, así como del cúmulo de estrategias, técnicas y recursos. Además, refiere que la autonomía del lector está ligada a la libertad y la voluntad, por lo que un docente lector tiene entre sus prioridades la adquisición de libros según sus intereses y necesidades pedagógicas y de disfrute. Para el docente historiador, todo docente lector es 'escribidor' formal o informal, cuyos primeros lectores tendrían que ser sus estudiantes, en quienes con sus escritos enfatiza la motivación que ejerce. 
El docente 3 plantea que un docente lector es aquel que lee con interés y motivación información confiable, interactúa con los textos tomando notas, resumiendo, generándose espacios de autorreflexión, teniendo curiosidad y constancia, hasta lograr la satisfacción de haber comprendido la información que le permita fortalecer sus aprendizajes para mejorar el ejercicio de su labor docente. Afirma que para formar lectores es vital que el docente sea lectoescritor, solo así podrá comprender las dificultades, necesidades e intereses de sus estudiantes cuando se trata de incentivarlos a leer y escribir; de lo contrario, o bien el estudiante no leerá o lo hará por obligación. Además, según el entrevistado, es necesario que el docente esté familiarizado con libros físicos y digitales, que está habituado a compartir sus lecturas recientes con sus estudiantes y su círculo de trabajo, ya sea de manera presencial o no presencial, generando espacios de reflexión, diálogo y discusión, utilizando recursos tecnológicos a los que tienen más acceso los niños y adolescentes como el WhatsApp.

Respecto al rol del docente como mediador de la formación de lectores se encontró lo siguiente:

Para el docente 1, la mediación con amor filial por el libro comienza en los primeros años de escolaridad, y consiste en emplear diferentes mecanismos de lectura y no únicamente en la oralización de grafías. Por una parte, en cuanto a su metodología, refiere que ejecuta una secuencia didáctica de formación de lectores en el que existe interacción constante, que en líneas generales comienza en la búsqueda de generar predisposición, la libertad del lector al elegir el texto que genere el vínculo texto-lector; seguida de enseñanza de las bases teóricas de la comprensión de la lectura $\mathrm{y}$, por último, el estudiante se enfrente a textos de diversas modalidades. También responde que utiliza estrategia como fanfiction en lecturas de ficción y la 'lectura conexión', que consiste en que el estudiante elige tres razones para leer que lo implican a él y al libro. Por otra parte, asevera que los estudiantes de la actualidad están sumidos en las redes sociales con frecuencia y prefieren leer los textos breves de ficción que estén conectados con el lector. Por último, opina que el docente tendrá que enfrentar las limitantes que constituyen las programaciones del Ministerio de Educación cuando se trata de formar lectores, en tener que cumplirlas pese a contener temas periféricos al eje lector, porque desde su percepción el Currículo Nacional de Educación Básica vigente no está diseñando para tal fin.

Según el docente 2 para formar lectores, cada estudiante debe contar con su texto, la motivación, la voluntad y la atención esté orientada a la comprensión, a distinguir un buen texto, a deducir las ideas relevantes, y para ello se requiere de técnicas. Durante su labor docente al formar lectores, refiere que desarrolla tres fases: primero, diagnostica la naturaleza, el propósito de los textos, así como los intereses, motivaciones de sus estudiantes, selecciona textos que progresivamente serán de mayor extensión en sucesivas sesiones, los textos son de narrativa breve, motivación personal y cultura nacional y universal según el nivel de escolaridad; luego, durante el proceso de la lectura, 
refiere que inicia su sesión utilizando frases motivadoras, lemas o pensamientos que están contenidas en el texto que se leerá, luego explica el contexto del texto y la trascendencia del autor, enseguida aplica técnicas, entre ellas el subrayado, el diálogo a partir de preguntas, motivando, mostrando paciencia y empatía con sus estudiantes. En la fase final, dialogan sobre el contenido de lo leído, asumen compromisos y elaboran un resumen. Bajo la consigna de 'leemos todos', considera importante que el docente sea promotor de la lectura comprensiva, que comprometa la participación de la familia y conforme colectivos de lectores-escritores para generar hábitos lectores en la escuela. Una de las limitantes para el docente, según su percepción, es que el Currículo Nacional no está diseñado para formar lectores, solo contiene lineamientos generales sobre lectura y escritura dentro de múltiples competencias que pretende desarrollar.

Para el docente 3, la formación de lectores implica la selección asertiva de materiales de lectura acorde a los temas de interés, requiere de monitoreo constante, de espacios de aprendizaje, diálogo y opinión. Según su apreciación la formación de lectores debe permitir también el desarrollo de las competencias de otras áreas curriculares, así como las competencias transversales. Durante la sesión, propone lecturas adaptadas a la realidad y las necesidades de los estudiantes, situaciones auténticas como insumo de motivación que le ayuden a mejorar su comprensión, mediante preguntas retadoras y entrega de evidencias de lectura. Según su percepción, el Currículo Nacional sí permite formar lectores, advierte que el problema es la omisión o el error de los docentes en el desarrollo de desempeños y capacidades de las competencias.

\section{Discusión}

En cuanto a las características del docente se encontró que los tres entrevistados reúnen el perfil de docente lector planteado por Garrido (2004): lee asiduamente por voluntad, está habituado a la comprensión, adquiere acervos, se sirve de la escritura, generan conciencia lectora individual y social en los estudiantes. Los tres docentes coinciden en sus concepciones sobre la lectura, su importancia, su rol, sus características y sus prácticas de formación de lectores están sustentadas en los principios de libertad (Sánchez, 1988; Pennac, 1992; Robles, 2006; Cisneros, 2009), individualidad, vidaexistencia, acción-trascendencia, realidad y comunidad (Sánchez, 1987; 1988). El docente 1 hace énfasis en la importancia que el docente sea un ejemplo de lector, más aún en educación básica, de allí el desafío del docente de construirse como sujeto lector (Ferreyro \& Stramiello, 2008); ello también concuerda con lo que dice Coll (2004), que los estudiantes aprenden a sentir placer y gusto por la lectura cuando tienen modelos que andamien adecuadamente a este respecto. Estos modelos son primero los padres y después los docentes (Sánchez, 1988; Tovar, 2008). También se corresponde con la concepción de De Zubiria (2010) quien plantea tres etapas para un proceso de aprendizaje: la modelación del docente, el desempeño del estudiante con la mediación del docente, el desenvolvimiento autónomo del 
estudiante. No obstante, las investigaciones evidencian que el maestro no es un lector experto y que tiene serias limitaciones en su hábito lector $\mathrm{y}$ sus capacidades de interpretación de los textos (ÁlvarezÁlvarez y Diego-Mantecón, 2018; Colomer y Munita, 2013).

Los docentes 1 y 2 hacen alusión de manera explícita a los cuatro elementos, factores indispensables para llevar a cabo la formación de lectores según Sainz (2005), los acervos, el mediador; la libertad, tiempo $\mathrm{y}$ espacio $\mathrm{y}$, el ambiente estimulante. $\mathrm{Y}$ añaden a estos elementos: el plan de lectura. Al respecto, para el docente 2, su planeación es institucional y debe estar dirigido por los docentes del área de Comunicación. En cambio, para los docentes 1 y 3, la planificación debe empezar con el diagnóstico de las necesidades e intereses de los estudiantes realizado por cada docente de aula. Por otra parte, aunque coinciden en la planeación y el carácter transversal de la lectura, ninguno menciona la importancia de las políticas de libro, lectura y biblioteca articuladas dentro de un proyecto social y un plan nacional de desarrollo (Sánchez, 1988).

En cuanto al rol mediador del docente, el docente 2 afirma que utiliza estrategias antes, durante y después de la lectura comprensiva propuesta por Solé (1992; 2004) y desarrollan una secuencia didáctica que concuerdan con la idea general de planificación de una sesión de clases, inicio-proceso-cierre. En tanto, el docente 1, primero desarrolla la lectura libre, luego las bases teóricas de la compresión y finaliza el proceso con lecturas variadas. En cuanto al docente 3, este se ciñe al proceso didáctico establecido por el currículo nacional de educación básica, mediante proyectos de aprendizaje que culmina en la presentación de evidencias que incluyen tareas concretas a realizar: la lectura como tarea. Según Tovar (2008) la formación de lectores se concreta en las reflexiones que docente hace a cerca de sus procesos de lectura y escritura, la promoción del conocimiento de su propio proceso como lector, la participación en entornos de interacción con variedad de textos, lectores y círculos de lectores, propiciando el trabajo cooperativo con sus pares y desarrollando una didáctica propia. En contraste, se puede deducir que la labor pedagógica de los docentes 1 y 2 concuerda con las dos últimas dimensiones propuestos por Tovar. En cuanto al trabajo pedagógico el docente 3, por su característica autorreflexiva, concuerda con la primera dimensión. Además, enfatiza la necesidad de utilizar recursos tecnológicos y medios digitales para promover la lectura. Al respecto, Arbonés et al (2015) plantea que el proceso lector y las modalidades textuales están cambiando, y leer es más complejo con la aparición de textos multimodales (lecturas que combinan dos o más sistemas semióticos: efectos de sonido, lenguaje oral y escrito, imágenes fijas o en movimiento), el cual constituye un nuevo reto en la formación de lectores.

Finalmente, esta investigación por su naturaleza cualitativa presenta datos autoinformados de los entrevistados, cuyas opiniones sobre el tema no pueden ser verificados independientemente en la realidad, pero al ser congruentes con las fuentes consultadas no se advierte 
subjetividad evidente; sin embargo, constituye una limitación metodológica, por la memoria selectiva del informante clave, quien puede o no recordar experiencias o eventos relevantes sobre la formación de lectores.

\section{Conclusiones}

Los estudiantes aprenden a sentir placer y gusto por la lectura cuando tienen modelos que le guíen adecuadamente en este proceso. Estos modelos son primero los padres y después los docentes. Entonces, para tener una educación básica que forme lectores se necesita, como primer soporte, de docentes: a) que inviertan en su formación continua, tengan motivaciones relevantes para leer, se nutra de nuevos acervos continuamente reflexionando sobre su propio proceso lector y sus habilidades de comprensión de los textos; b) que sean asiduos lectores que se sirven de la escritura, cuyo rol mediador permita el vínculo libre entre estudiante lector y el libro a través de la autorreflexión, la modelación que supone enseñar con el ejemplo y la construcción coherente de una didáctica propia. La lectura debe estar entre sus prioridades, así como la adquisición de acervos de interés pedagógica y de disfrute;

\section{Referencias}

Álvarez-Álvarez, M y Diego-Mantecón, J. (2019). ¿Cómo describen, analizan y valoran los futuros maestros su formación lectora? Revista Complutense de Educación. 30(4), 1083-1096

http://repositorio.unican.es:8080/ xmlui/bitstream/handle/10902/1 c) que planifiquen los procesos de lectura libre, integrando la dualidad libro-lector, lectura-escritura, pero anteponiendo la lectura sobre la escritura. Leer más para escribir algo que puede ser leído y formar parte del diálogo lector-escrito; d) que planifique dando respuesta a objetivos que trasciendan, que vayan más allá de la comprensión de la lectura, como el realizar una publicación con los estudiantes. Una planificación pluridisciplinaria, trasversal e integradora basadas en diagnósticos, el trabajo cooperativo, la contextualización a situaciones auténticas, a las políticas de libro, lectura y biblioteca articuladas dentro de un proyecto social institucional; e) que selección los acervos con asertividad, pertinencia, sobre temas de interés de los estudiantes, requiere del monitoreo constante, de espacios de aprendizaje y diálogo; y f) que emplee una metodología o secuencia didáctica de formación de lectores que comience generando predisposición, vínculo texto-lector a través de la interacción constante. Sin embargo, existe dificultades que se evidencian en investigaciones recientes: que el maestro no es un lector experto y tiene limitaciones en su hábito lector, sus saberes $\mathrm{y}$ capacidades de interpretación de los textos.

7708/ComDescribenAnalizan.pdf?s equence $=3 \&$ isAllowed $=y$

Álvarez-Álvarez, C., y Pascual-Díez, J. (2013). Estudio de caso sobre la formación de lectores críticos mediante textos literarios en la Educación Primaria. Ocnos: Revista 
de estudios sobre lectura, 10, 27-53. https://revista.uclm.es/index.php/ ocnos/article/view/ocnos 2013.10 .02

Álvarez-Álvarez, C., \& Pascual-Díez, J. (2020). Formación inicial de maestros en promoción de la lectura y la literatura en España desde la perspectiva del profesorado universitario. Revista iberoamericana de educación superior, 11(30), 57-75. http://www.scielo.org.mx/scielo.p hp?pid=S2007$\underline{28722020000100057 \& \text { script }=\text { sci a }}$ rttext

Arbonés, C., Mendoza, A., Muñoz, M., Prats, M. y Sanahuaja, E. (2015). Textualidades multimodales, conectividad y redes 2.0 en el aula: sobre la educación literaria y el profesorado en formación. In Redes hipertextuales en el aula: Literatura, hipertextos y cultura digital. Octaedro.

https://dialnet.unirioja.es/servlet/ articulo?codigo $=7171556$

Caro, D., Espinosa, G., Montané, A., y Tam, M. (2004). Una aproximación a la alfabetización lectora de los estudiantes peruanos de 15 años: Resultados del Perú en la evaluación internacional PISA. http://repositorio.minedu.gob.pe/ handle/123456789/101

Chase, S., Denzin, N. y Lincoln, Y. (2015). Investigación narrativa. Métodos de recolección y análisis de datos. Manual de Investigación Cualitativa
Volumen IV, 58-citation_lastpage. https://books.google.es/books?hl= es\&lr $=\& \mathrm{id}=5 \mathrm{pPsDwAAQBAJ \& oi=fn}$ $\underline{\mathrm{d} \& \mathrm{pg}=\mathrm{PT} 55 \& \mathrm{dq}=\text { susan }+ \text { chase } .+\mathrm{me}}$ todo+narrativo\&ots $=$

Cisneros, L. (3 de marzo de 2009). Leer es saber leer. La República, 3. http://leerydifundir.blogspot.com/ 2009/03/leer-es-saber-ver.html

Colomer, T. y Munita, F. (2013). La experiencia lectora de los alumnos de Magisterio: nuevos desafíos para la formación docente. Lenguaje $y$ Textos, 38, 37-44. http://www.sedll.org/sites/default /files/journal/la experiencia lecto ra de los alumnos de magisterio. colomer t.pdf

Cueto, S., León, J., Muñoz, I. y Rosales, E. (2016). Conductas, estrategias y rendimiento en lectura en PISA: análisis para el Perú. REICE: Revista Iberoamericana sobre Calidad, Eficacia y Cambio en Educación, 14(3), 5-31. https://dialnet.unirioja.es/servlet/ articulo?codigo $=5536818$

De Zubiría, J. (2006). Modelos pedagógicos. Hacia una pedagogía dialogante. Magisterio. Ampersan.

De Zubiría, M. (2010). Universidad Norbert Wiener (2009). III Congreso internacional de formación docente. En De Zubiria, M. (ponente), Pedagogías y didácticas contemporáneas en la educación superior. 
Devetach, L. (2008). La construcción del camino lector. Comunicarte. https://scholar.google.es/scholar? hl=es\&as sdt=0\%2C $5 \& \mathrm{q}=$ Devetach \%2C+L.+\%282008\%29.+La+constr ucci\%C3\%B3n+del+camino+lector \&btnG $=$

Dutra, E. (2002). A narrativa como una técnica de pesquisa fenomenológica. Estudios de Psicología (Natal), 7(2), 371-378. https://www.scielo.br/scielo.php? pid=S1413$\underline{294 X 2002000200018 \& \text { script }=\text { sci a }}$ rttext\&tlng=pt

Ferreyro, J., y Stramiello, C. I. (2008). El docente: el desafío de construir/se en sujeto lector. Revista Iberoamericana de Educación, 45(4), 1-7. http://profefelipe.mex.tl/imagesne $\mathrm{w} / 7 / 4 / 6 / 3 / 6 /$ EL $\% 20 D O C E N T E \%$ 20Y\%20LA\%20LECTURA.pdf

Feuerstein, R. (1993). Modificabilidad cognitiva y programa de enriquecimiento instrumental. Manual para el alumno y el docente. Instituto Superior Pio X.

Garrido, F. (2004). El buen lector se hace, no nace. Reflexiones sobre lectura $y$ formación de lectores. Ediciones del Sur.

Lerner, D. (2002). La autonomía del lector. Un análisis didáctico. Lectura $y$ vida, 23(3), 6-19. http://servicios.abc.gov.ar/lainstit ucion/organismos/lecturayescritur a/recomendados/23-3Lerner.pdf

Martínez, M. (2015). Epistemología y metodología cualitativa en ciencias sociales. Trillas.
Martínez-Salgado, C. (2011). El muestreo en investigación cualitativa. Principios básicos y algunas controversias. Universidad

Autónoma Metropolitana. https://www.scielosp.org/pdf/csc/ 2012.v17n3/613-619/es

Mendoza-Valdés, R., y Cardoso-Malaquias, R. (2016). Ética en la formación de lectores. Una aproximación hermenéutica.

http://148.215.1.182/bitstream/h andle $/ 20.500 .11799 / 98474 / 4463$ 47893008.pdf?sequence $=1$

Merlo, A. (2020). Habilidades complejas de lectura en el posgrado. ¿Formación o disonancia? Editorial Universidad de Guadalajara. https://books.google.es/books?hl= es\&

Mertens, D. (2014). Research and evaluation in education and psychology: Integrating diversity with quantitative, qualitative, and mixed methods. Sage publications.

Not, L. (1983). Las pedagogías del conocimiento. Fondo de Cultura Económica.

Patton, M. (1990). Qualitative evaluation and research methods. SAGE Publications, inc.

Pennac, D. (2004). Como una novela. Norma. https://scholar.google.es/scholar?

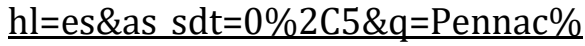
2C+D.+\%282004\%29.+Como+una+ novela\&btnG=

PISA, OCDE (2011). ¿Leen actualmente los estudiantes por placer? PISA in Focus, 8. http://repositorio.minedu.gob.pe/ 
bitstream/handle/123456789/429 0/Leen $\% 20$ actualmente $\% 20 \operatorname{los} \% 2$ 0estudiantes\%20por\%20placer.pd f?sequence $=1$ \&isAllowed $=y$

Ramaprasad, A. (1983). On the definition of feedback. Behavioral science, 28(1), 4-13.

https://onlinelibrary.wiley.com/do $\mathrm{i} / \mathrm{abs} / 10.1002 / \mathrm{bs} .3830280103$

Kaben, A. (2009). El docente como mediador intercultural. Actas del I taller de literatura hispánicas y E/le, 29-31.

https://cvc.cervantes.es/Ensenanz a/Biblioteca Ele/publicaciones cen tros/PDF/oran 2009/14 kaben.pdf

Robles, E. (2006). Si no leo, me a-burro. Método para convertir la lectura en un placer. Debolsillo.

Salado, A. (2007). Investigación cualitativa: diseños, evaluación del rigor metodológico $\mathrm{y}$ retos. Liberabit, 13(13), 71-78. http://www.scielo.org.pe/scielo.ph p?pid=S1729$\underline{48272007000100009 \& \text { script }=\text { sci a }}$ rttext\&tlng=en

Sánchez, D. (1987). Lectura en Educación Primaria, una investigación.
Instituto Nacional de Investigación y Desarrollo de la Educación.

Sánchez, D. (1988). La aventura de leer. Paramonga.

Sánchez, D. (2004). Estrategias didácticas para la comprensión lectora: Educación Básica. Universidad Nacional Mayor de San Marcos.

Sainz, L. (2005). La importancia del mediador: una experiencia en la formación de lectores. http://www.ince.mec.es/revistaed ucacion/re2005/re2005a024.pdf

Solé, I. (1992). Estrategias de comprensión de la lectura. Cuadernos de pedagogía, 216, 25-27. http://www.lecturayvida.fahce.unl p.edu.ar/numeros/a17n4/17 04 S ole.pdf

Solé, I. (2004). Estrategias de lectura. Graó.

Tovar, R. (2008). La formación como lector y escritor: Un reto para el docente. Educere, 13(44), 109-116. https://www.redalyc.org/pdf/356 35614571013.pdf

Wallon, H. (1984). La evolución psicológica del niño. Grijalbo.. 